\title{
EFEITO DAS DIFERENTES PLANTAS DE COBERTURA EM FEIJÃO ORGÂNICO SOB PLANTIO DIRETO
}

\author{
Guilherme Constantino Meirelles ${ }^{1}$
}

Carolina dos Santos Batista Bonini ${ }^{2}$

Neli Cristina Belmiro dos Santos ${ }^{3}$

\begin{abstract}
RESUMO O feijão tem grande importância na alimentação, principalmente por ser uma fonte de proteína, desse modo apresenta destaque para o cultivo orgânico, que é um cultivo mais sustentável, utilizando assim coberturas de solo para auxiliar no manejo sustentável. O objetivo do trabalho foi avaliar os atributos físicos de um Latossolo em sistema plantio direto de feijão orgânico implantado no ano de 2015. O experimento foi realizado no município de AndradinaSP. O delineamento utilizado foi em blocos casualizados, com quatro repetições e composto por oito tratamentos: Urochloa ruziziensis; Milheto; Crotalária juncea; Mucuna cinza; Urochloa ruziziensis + Crotalária juncea; Urochloa ruziziensis + Mucuna cinza; Milheto + Crotalária juncea; e, Milheto + Mucuna cinza. As avaliações realizadas foram: resistência mecânica a penetração e umidade gravimétrica do solo $(0-0,05 ; 0,05-0,10$ e $0,10-0,20 \mathrm{~m})$; taxa de infiltração de água; e a produtividade de feijão orgânico. Os tratamentos estudados não influenciaram a resistência a penetração, bem como ocorreu para a umidade e a taxa de infiltração de água no solo. A produtividade do feijão orgânico sofreu influência das espécies de cobertura do solo.
\end{abstract}

PALAVRAS-CHAVE: Phaseolus vulgaris. Palhada. Física do solo.

\section{EFFECT OF DIFFERENT COVER CROPS IN BEAN ORGANIC}

\section{UNDER NO-TILLAGE}

ABSTRACT The beans have great importance in food, mainly because it is a source of protein, thus presents emphasis on organic farming, which is more sustainable farming, thereby using cover crops to assist in sustainable management. The objective was to evaluate the physical attributes of an Oxisol in no-till organic beans system implemented in 2015. The experiment was conducted in the city of Andradina-SP. The design was a randomized block design with four replications and eight treatments consisting of: Urochloa ruziziensis; Pennisetum glaucum; Crotalária juncea; Mucuna pruriens; Urochloa ruziziensis + Crotalária juncea; Urochloa ruziziensis + Mucuna pruriens; Pennisetum glaucum + Crotalária juncea; and, Pennisetum glaucum + Mucuna pruriens; . The evaluations were: mechanical resistance to penetration and gravimetric soil moisture (0-0.05; 0.05-0.10 and 0.10-0.20 m); water infiltration rate; and organic

\footnotetext{
${ }^{1}$ Aluno de pós-graduação em Ciência e Tecnologia Animal, Universidade Estadual Paulista, UNESP. CEP 17900-000, Dracena, São Paulo, Brasil. gui_meirelles2312@hotmail.com. ${ }^{2}$ Docente do Curso de Engenharia Agronômica, Universidade Estadual Paulista, UNESP. CEP 17900-000, Dracena, São Paulo, Brasil. E-mail: carolbonini@dracena.unesp.br. 3 Pesquisadora Científica IV da Agência Paulista de Tecnologia dos Agronegócios (APTA), Caixa Postal 67 - CEP 16900-970 Andradina, São Paulo, Brasil. neli@apta.sp.gov.br.
} 


\section{Periódica Eletrânica

bean productivity. The treatments did not influence the resistance to penetration and occurred for moisture and water infiltration rate in the soil. The productivity of organic bean was influenced by soil cover crops.

KEY WORD: Phaseolus vulgaris. Straw. Soil physics.

\section{EFECTO DE LOS CULTIVOS DE COBERTURA DISTINTOS EN FRIJOLES ORGÁNICOS BAJO SIEMBRA DIRECTA}

RESUMO Los frijoles tienen una gran importancia en la alimentación, sobre todo porque es una fuente de proteínas, por lo tanto presenta énfasis en la agricultura ecológica, que es una agricultura más sostenible, utilizando para ello los cultivos de cobertura para ayudar en la gestión sostenible. El objetivo fue evaluar los atributos físicos de un Oxisol en sistema de siembra frijoles orgánicos en marcha en 2015. El experimento se llevó a cabo en el municipio de Andradina-SP. El diseño fue de bloques al azar con cuatro repeticiones y ocho tratamientos que consisten en: Urochloa ruziziensis; Pennisetum glaucum; Crotalária juncea; Mucuna pruriens; Urochloa ruziziensis + Crotalária juncea; Urochloa ruziziensis + Mucuna pruriens; Pennisetum glaucum + Crotalária juncea; e, Pennisetum glaucum + Mucuna pruriens;: Las evaluaciones fueron: resistencia mecánica a la penetración, la humedad del suelo $(0$ a 0,05; 0,05-0,10 y 0,10-0,20 m); tasa de infiltración del agua; y la productividad del frijol orgánico. Los tratamientos no influyen en la resistencia a la penetración, la humedad y el agua de infiltración en el suelo. La productividad de los granos orgánicos fue influenciado por las especies cobertura del suelo.

PALAVRAS-CLAVE: Phaseolus vulgaris. Paja. Física del suelo.

\section{INTRODUÇÃO}

O feijão comum (Phaseolus vulgaris, L.) tem destaque na produção brasileira e mundial, não apenas pelo enfoque econômico, mas por sua importância na segurança alimentar, valor nutricional e por fazer parte da cultura culinária em vários países (EMBRAPA, 2012).

A área plantada no Brasil na safra 2013/2014 era de 3.350 .400 hectares, isso somando a primeira, segunda e terceira safra, com produtividade média de $1024 \mathrm{~kg} / \mathrm{ha}$, com produção total de 3.431,6 toneladas (CONAB, 2014).

Para melhora da produção do feijoeiro tem se usado sistemas conservacionistas como o plantio direto (EMBRAPA, 2012).

Houve aumento da demanda por feijão orgânico, ainda que os valores sejam maiores em 30 a $40 \%$ em relação ao feijão produzido convencionalmente, pelo fato do feijão orgânico ter como benefício o não uso 


\section{Periádica Eletrânica

de fungicidas, inseticidas, herbicidas e adubos químicos, consequentemente reduzindo o risco à saúde dos produtores, dos consumidores e os danos ao ambiente, tornando um sistema sustentável, com utilização de adubos verdes, compostos orgânicos, dejetos animais e resíduos agroindustriais (APTA, 2011).

O cultivo orgânico não somente substitui adubos minerais por orgânicos, esse sistema visa utilizar de maneira racional os recursos ambientais não renováveis. Um fator que pode contribuir com o cultivo orgânico é o uso de plantas de cobertura, que favorece a ciclagem de nutrientes, contribuindo com a fertilidade do solo, além de melhorar os aspectos físicos e biológicos no solo (EMBRAPA, 2006).

As plantas de cobertura ainda apresentam um maior teor de matéria orgânica no solo, gerando benefícios nos agregados do solo (CUNHA, et al., 2011).

Tornado uma opção para acrescentar matéria orgânica no solo com utilização da adubação verde, que protege o solo contra processos erosivos e evitando a brotação de plantas indesejáveis na área de cultivo, ainda com a finalidade de produção de massa para formar palhada para o plantio direto (EMBRAPA, 2008).

Esse sistema de cultivo pode alcançar médias de produtividade acima de $2000 \mathrm{~kg}$, oque viabiliza a produção do feijão orgânico que supera a média nacional (APTA, 2011).

O uso de preparo de solo e plantas de cobertura no cultivo orgânico são de extrema importância, não apenas para um maior rendimento, como para preservar a capacidade de produção do solo no decorrer dos anos, e contribuir para a conservação da qualidade física do solo (CUNHA, et al., 2011).

Com o cultivo orgânico há preocupação com a qualidade do solo, priorizando o mínimo revolvimento do solo e acréscimo ou manutenção da matéria orgânica, que colaboram para conservação e melhora nos atributos químicos, físico e biológicos do solo (EMBRAPA, 2008).

A estrutura do solo é de grande importância para espécies se adaptarem e tem como avaliação a densidade e agregados do solo, resistência mecânica a penetração, macro e microporosidade (LAURINDO, et al,. 2009). 
Comumente o aumento da matéria orgânica contrafaz a densidade do solo, em que com maior teor de matéria orgânica há floculação do solo, que aumenta os espaços livres impedindo a compactação (LAURINDO, et al,. 2009).

De acordo com Moreira et al., (2008) as diferentes coberturas de solo tem efeito sobre a física do solo, bem como a quantidade de massa produzida, que auxilia na melhora dos valores de densidade do solo, microporosidade, macroporosidade e porosidade total.

Em sistemas que são utilizados plantas de cobertura fixadoras de nitrogêncio há incremento na produção do milho verde, isso devido a maior ciclagem de nutrientes, um exemplo prático é a mucuna-preta que acumula quantidades superiores de certos nutrientes quando comparada a outras espécies de plantas de cobertura (BARROS et al., 2013).

As coberturas vegetais além de ter efeito nos atributos físicos do solo, tem influência sobre a disponibilidade de nutrientes, como fonte de nitrogênio, auxilia na reciclagem de nutrientes lixiviados e disponibiliza o fósforo para as plantas, além de reestruturar o solo, reduzir quantidade de plantas daninhas e controlando a população de pragas (APTA, 2011).

\section{OBJETIVOS}

O objetivo deste trabalho foi avaliar a qualidade física de um Latossolo Vermelho em sistema de cultivo de feijão orgânico por meio de avaliação dos atributos físicos e produtividade do feijoeiro.

\section{METODOLOGIA}

O experimento foi conduzido na Agência Paulista de Tecnologia dos Agronegócios (APTA), Pólo Regional de Andradina, no município de Andradina, no estado de São Paulo, localizado na região noroeste do estado a 379 metros de altitude, latitude $20^{\circ} 55^{\prime} \mathrm{S}$ e longitude $51^{\circ} 23^{\prime} \mathrm{W}$. O solo é classificado como 
Latossolo Vermelho Amarelo distrófico (EMBRAPA, 2013). A precipitação média anual é de $1150 \mathrm{~mm}$, e temperatura média anual de $23 \stackrel{\circ}{\circ} \mathrm{C}$.

O experimento está delineado em blocos casualizados, sendo os tratamentos diferentes plantas de cobertura, sendo eles:

1. Urochloa ruziziensis;

2. Pennisetum glaucum;

3. Crotalária juncea;

4. Mucuna pruriens;

5. Urochloa ruziziensis + Crotalária juncea;

6. Urochloa ruziziensis + Mucuna pruriens;

7. Pennisetum glaucum + Crotalária juncea;

8. Pennisetum glaucum + Mucuna pruriens.

A semeadura do feijoeiro foi realizada no mês de abril, efetuada manualmente em espaçamento de 0,45 m entre linhas, com distribuição de 12 sementes viáveis por metro e aplicação do fertilizante orgânico Organomais $\AA$ com dose de 4 toneladas/ha na forma de farelo.

As irrigações foram realizadas com aspersores convencionais, com o manejo de irrigação realizado conforme a necessidade da cultura.

O controle de plantas daninhas foi efetuado com capina manual aos 10 dias após a emergência (DAE) do feijão e sempre quando necessário com a utilização da roçadeira manual nas entrelinhas para o controle de rebrotas das plantas de cobertura.

Foram analisados os seguintes atributos do solo e da planta:

- Taxa de infiltração: foi realizada com a utilização do Infiltrômetro Mini Disk (ZANG, 1997) o qual foi colocado sobre a superfície do solo, sobre uma fina camada de areia para assegurar contato hidráulico adequado entre o disco e o solo. As leituras foram realizadas a cada 30 segundos, até a taxa de infiltração permanecer constante, com o aparelho ajustado para uma sucção h0 igual a $2 \mathrm{~cm}$. Foi determinada em três pontos distintos em cada parcela experimental, de forma a obter dados homogêneos. 
- Resistência do solo à penetração: foi utilizado penetroLOG, modelo Falker, Automação Agrícola, em três pontos por parcela, nas camadas de 0,00-0,05; 0,05-0,10 e 0,10-0,20 m.

- Umidade gravimétrica do solo pelo método clássico de pesagem (EMBRAPA, 1997), nas camadas de 0,00-0,05; 0,05-0,10 e 0,10-0,20 $\mathrm{m}$, no mesmo momento da determinação da resistência a penetração.

- Produtividade do feijão: a colheita do experimento foi realizada manualmente na área útil em cada parcela, quando 95\% das vagens apresentaram a coloração típica de vagem madura, após a colheita foram debulhados em máquina trilhadeira estacionária e as sementes foram limpas com auxílio de peneiras e colocadas em sacos de papel, pesadas para determinação da produção, e cálculo da produtividade em $\mathrm{kg} / \mathrm{ha}$ a $13 \%$ de umidade (base úmida).

Os dados obtidos foram submetidos à análise de variância e ao teste $F$, e as médias comparadas pelo teste de Tukey a 5\% de significância através do programa SISVAR.

\section{RESULTADOS E DISCUSSÃO}

Os dados de resistência a penetração e umidade do solo estão apresentados na Tabela1.

Os valores médios de resistência a penetração (Tabela 1) nas profundidades de 0,00-0,05 0,05-0,10 e 0,10-0,20 $\mathrm{m}$, o estudo não foi significativos para os diferentes tipos de coberturas vegetais. O que concorda com Cunha et al., (2011) em que também não observou diferença significativa na resistência do solo a penetração dentre as coberturas de solo. E segundo Barros et al., (2013) as plantas de cobertura promovem ainda uma proteção do solo contra erosão, além de proporcionar maior produtividade da cultura principal em relação ao tratamento em pousio.

A umidade do solo nas diferentes profundidades de 0,00-0,05 0,05-0,10 e 0,10-0,20 m não foram influenciados pelas diferentes espécies de cobertura do solo. Fato também observado por Cunha et al., (2011) em que os valores 
médios de umidade do solo não foram influenciados pelo tipo de cobertura de solo.

A importância da determinação do grau de umidade do solo no mesmo tempo em que se faz o teste de resistência a penetração, se dá ao fato que dependendo da umidade do solo há maior ou menor coesão entre as partículas do solo, que em solo seco apresenta maior coesão e conforme aumenta a quantidade de água a coesão decresce, gerando separação das partículas (KLEIN et al., 1998).

Segundo Canarache (1990) os valores de resistência a penetração encontrados nesse trabalho estão abaixo do limite crítico ao desenvolvimento radicular das plantas que é de 2,5 $\mathrm{MPa}$.

Tabela 1: Valores médios de resistência a penetração $(\mathrm{MPa})$ e umidade gravimétrica do solo ( $\mathrm{kg} \mathrm{kg}^{-1}$ ), nos tratamentos estudados nas camadas de 0,00-0,05 0,05-0,10 e 0,10-0,20 m, Andradina - SP, 2015.

\begin{tabular}{|c|c|c|c|c|c|c|}
\hline \multirow[b]{2}{*}{ Tratamento } & RP1 & RP2 & RP3 & UG1 & UG2 & UG3 \\
\hline & \multicolumn{3}{|c|}{-------------MPa----------- } & \multicolumn{3}{|c|}{--- } \\
\hline $\begin{array}{l}\text { Urochloa } \\
\text { ruziziensis }\end{array}$ & 1,35 & 1,14 & 1,04 & 0,0950 & 0,0975 & 0,1000 \\
\hline $\begin{array}{l}\text { Pennisetum } \\
\text { Glaucum }\end{array}$ & 1,31 & 1,29 & 1,06 & 0,0970 & 0,1000 & 0,1050 \\
\hline Crotalária Juncea & 1,40 & 1,10 & 1,03 & 0,0825 & 0,950 & 0,0975 \\
\hline $\begin{array}{l}\text { Mucuna pruriens } \\
\text { Urochloa }\end{array}$ & 1,32 & 1,13 & 1,03 & 0,0900 & 0,1000 & 0,0975 \\
\hline $\begin{array}{c}\text { ruziziensis + } \\
\text { Crotalaria Juncea } \\
\text { Urochloa }\end{array}$ & 1,25 & 1,20 & 1,03 & 0,0875 & 0,0975 & 0,1000 \\
\hline $\begin{array}{c}\text { ruziziensis + } \\
\text { Mucuna pruriens } \\
\text { Pennisetum }\end{array}$ & 1,22 & 1,14 & 1,03 & 0,0875 & 0,1025 & 0,1025 \\
\hline $\begin{array}{l}\text { Glaucum + } \\
\text { Crotalária Juncea } \\
\text { Pennisetum }\end{array}$ & 1,36 & 1,16 & 1,02 & 0,0850 & 0,0975 & 0,1075 \\
\hline $\begin{array}{c}\text { Glaucum + Mucuna } \\
\text { pruriens }\end{array}$ & 1,25 & 1,28 & 1,18 & 0,0925 & 0,0975 & 0,1000 \\
\hline $\mathrm{F}$ & $1,169^{\text {ns }}$ & $1,339^{n s}$ & $1,399^{\mathrm{ns}}$ & $0,541^{\mathrm{ns}}$ & $0,576^{n s}$ & $0, \underset{\mathrm{ns}}{0,857}$ \\
\hline CV (\%) & 8,74 & 10,61 & 8,59 & 15,39 & 6,13 & 7,54 \\
\hline
\end{tabular}

*significativo a $5 \%$ de probabilidade e NS não significativo. Médias seguidas de letras distintas nas colunas diferem entre si, pelo teste de Tukey a $5 \%$ 
Os dados de infiltração de agua no solo e da produtividade do feijão estão apresentados na tabela 2.

Os valores médios de taxa de infiltração (Tabela 2 e Figura 1) não foram influenciados pelas coberturas de solo.

Segundo Brandão et al., (2006) os valores médios de taxa infiltração de água estão em entre adequados para solo arenoso, no qual a taxa de infiltração não interfere na produtividade da cultura, não limitando assim o seu desenvolvimento.

Os valores médios de produtividade do feijão orgânico foram influenciados pelas espécies de cobertura do solo, com maior produtividade sobre a cobertura de Crotalária juncea, e menor valor para a espécie de cobertura Mucuna pruriens, em que a Crotalária apresentou ser 27,32\% superior a Mucuna purpuriens. Segundo Barros et al., (2013) as leguminosas auxiliaram no aumento de produtividade da cultura principal.

Assim não se observa uma correlação entre as características do solo e a produtividade, na qual a taxa de infiltração obteve valores semelhantes para a Crotalária juncea e a Mucuna purpuriens, maior e menor produtividade, respectivamente. 
Tabela 2: Infiltração média acumulada $\left(\mathrm{mm} \mathrm{h}^{-1}\right)$ e produtividade do feijão orgânico $\left(\mathrm{kg} \mathrm{ha}^{-1}\right)$ para os tratamentos estudados, Andradina - SP, 2015.

\begin{tabular}{ccc} 
Tratamento & Produtividade (kg/ha) & $\begin{array}{c}\text { Taxa de infiltração } \\
(\mathrm{mm} / \mathrm{h})\end{array}$ \\
\hline Urochloa ruziziensis & $1829 \mathrm{ab}$ & 37,09 \\
Pennisetum Glaucum & $1630 \mathrm{ab}$ & 45,36 \\
Crotalária Juncea & $2064 \mathrm{a}$ & 46,23 \\
Mucuna pruriens & $1500 \mathrm{~b}$ & 47,12 \\
Urochloa ruziziensis + Crotalaria & $1697 \mathrm{ab}$ & 39,95 \\
$\begin{array}{c}\text { Juncea } \\
\text { Urochloa ruziziensis + Mucuna } \\
\text { pruriens }\end{array}$ & $1525 \mathrm{ab}$ & 43,41 \\
$\begin{array}{c}\text { Pennisetum Glaucum + Crotalária } \\
\text { Juncea }\end{array}$ & $1674 \mathrm{ab}$ & 35,37 \\
Pennisetum Glaucum + Mucuna \\
pruriens
\end{tabular}

*significativo a $5 \%$ de probabilidade e NS não significativo. Médias seguidas de letras distintas nas colunas diferem entre si, pelo teste de Tukey a $5 \%$.

\section{CONCLUSÃO}

Os diferentes tipos de cobertura de solo não provocaram alterações nos atributos resistência a penetração do solo, bem como ocorreu para a umidade do solo e a taxa de infiltração de agua no solo. 
Quadro 1: Infiltração acumulada de agua no solo nos tratamentos: (a) U. ruziziensis; (b) Pennisetum glaucum; (c) Crotalaria juncea; (d) Mucuna pruriens; (e) U.ruzizensis + $C$. juncea; (f) $U$. ruziziensis + M. pruriens; (g) $P$. glaucum $+C$. juncea e (h) $P$. glaucum $+M$. pruriens.

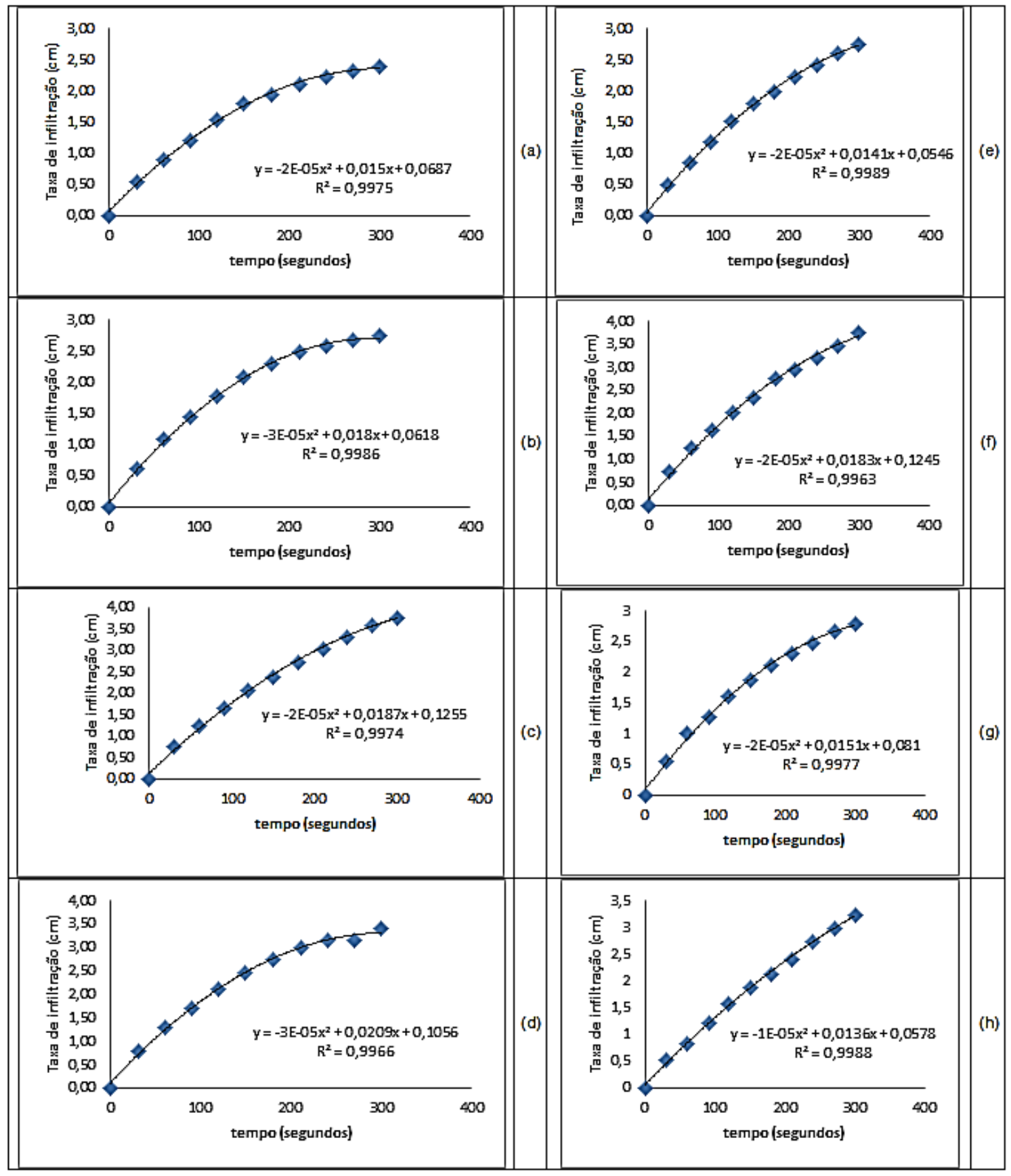

A produtividade sofreu efeito das coberturas de solo, com destaque para a Crotalária juncea, que promoveu melhores condições ao desenvolvimento da cultura principal e a menior produtividade para a Mucuna pruriens. 


\section{Periódica Eletrônica

\section{REFERÊNCIAS BIBLIOGRÁFICAS}

AGÊNCIA PAULISTA DE TECNOLOGIA DOS AGRONEGÓCIOS-APTA. Potencialidades de produção do feijão orgânico. Pesquisa \& Tecnologia, vol. 8, n. 2, Jul-Dez 2011.

BARROS, D.L.; GOMIDE, P.H.O.; CARVALHO, G.J. Plantas de cobertura e seus efeitos na cultura em sucessão. v. 29, n.2. Biosfera J. Uberlândia. P. 308-318. 2013.

BRANDÃO, V.S.; CECÍLIO, R.A.; PRUSKI, F.F.; SILVA, D.D. Infiltração de água no solo. Viçosa: Universidade federal de viçosa. Ed. 3. 120p. 2006.

CANARACHE, A, Penetr - a generalized semi-empirical model estimating soil resistance to penetration. Soil and Tillage Research, Amsterdam, v. 16, p. 51-70, 1990.

COMPANHIA NACIONAL DE ABASTECIMENTO. Acompanhamento de safra brasileira: grãos, terceiro levantamento safra 2014/15, n. 3. Dezembro/2014. Brasília: Companhia nacional de abastecimento -Conab, 2014. 100p.

CUNHA, E.Q; STONE, L.F.; MOREIRA, J.A.A.; FERREIRA, E.P.B.; DIDONET, A.D.; LEANDRO, W.M. Sistemas depreparo do solo e culturas de cobertura na produção orgânica de feijão e milho. I- Atributos físicos do solo. Revista Brasileira de Ciência do Solo, v. 35, p. 589602, 2011.

EMBRAPA - Empresa Brasileira de Pesquisa Agropecuária. Ministério da Agricultura, Pecuária e Abastecimento. Informações técnicas para o cultivo do feijoeiro-comum na Região Central-brasileira: 2012-2014. 1 ed. Santo Antônio de Goiás-GO, 2012. 248p.

EMBRAPA - Empresa Brasileira de Pesquisa Agropecuária. Ministério da Agricultura, Pecuária e Abastecimento. Manual de métodos de análise de solo. 2.ed. Rio de Janeiro: Embrapa CNPSO, 1997. 212p.

EMPRESA BRASILEIRA DE PESQUISA AGROPECUÁRIA (EMBRAPA AGROBIOLOGIA). Cultivo do café orgânico. Sistemas de Produção, n.2, ed.2. Dez 2006.

EMPRESA BRASILEIRA DE PESQUISA AGROPECUÁRIA (EMBRAPA HORTALIÇAS). Manejo do solo no sistema de produção orgânico de hortaliças. n.64, Brasília. 2008.

KLEIN, V. A.; LIBARDI, P. L.; SILVA, A. P. Resistência mecânica do solo à penetração sob diferentes condições de densidade e teor de água. Engenharia Agrícola, Piracicaba, v. 18, p. 45-54, 1998.

LAURINDO, M.C.O.; NÓBREGA, L.H.P; PERERA, J.O.; MELO, D.; LAURINDO, E.L. Atributos físicos do solo e teor de carbono orgânico em sistema de plantio direto e cultivo mínimo. Engenharia na agricultura. v. 17, n. 5. 2009, p. 367-374.

MOREIRA, J.A.A; RIGO, E.; STONE, L.F; CARVALHO, M. Plantas de cobertura de solo, preparo do solo e atributos físicos de um latossolo vermelho distrófico em sistema de produção orgânico. IX Simpósio Nacional Cerrado. ParlaMundi, Brasília. 2008.

ZANG, R. Determination of soil sorptivity and hydraulic conductivity from the disk infiltrometer. Soil Science Society of American Journal, 61:1024-1030, 1997. 